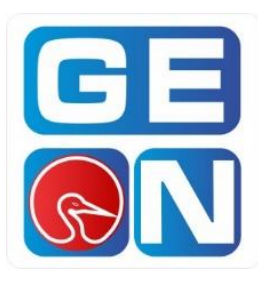

Revista GEON (Gestión, Organizaciones y Negocios.) ISSN: 2346-3910 en línea

revistageon@unillanos.edu.co

Universidad de los Llanos

Colombia

Lapa Guzman, Javier.

\title{
Un análisis teórico sobre el proceso de financiarización económica
}

Revista GEON, Vol. 4, No. 2, 2017

Pág. 125-145

Disponible en: $\underline{\text { https://doi.org/10.22579/23463910.30 }}$

Esta publicación se encuentra bajo licencia: Creative Commons

ReconocimientoNoComercialSinObraDerivada 4.0 Internacional

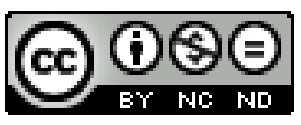

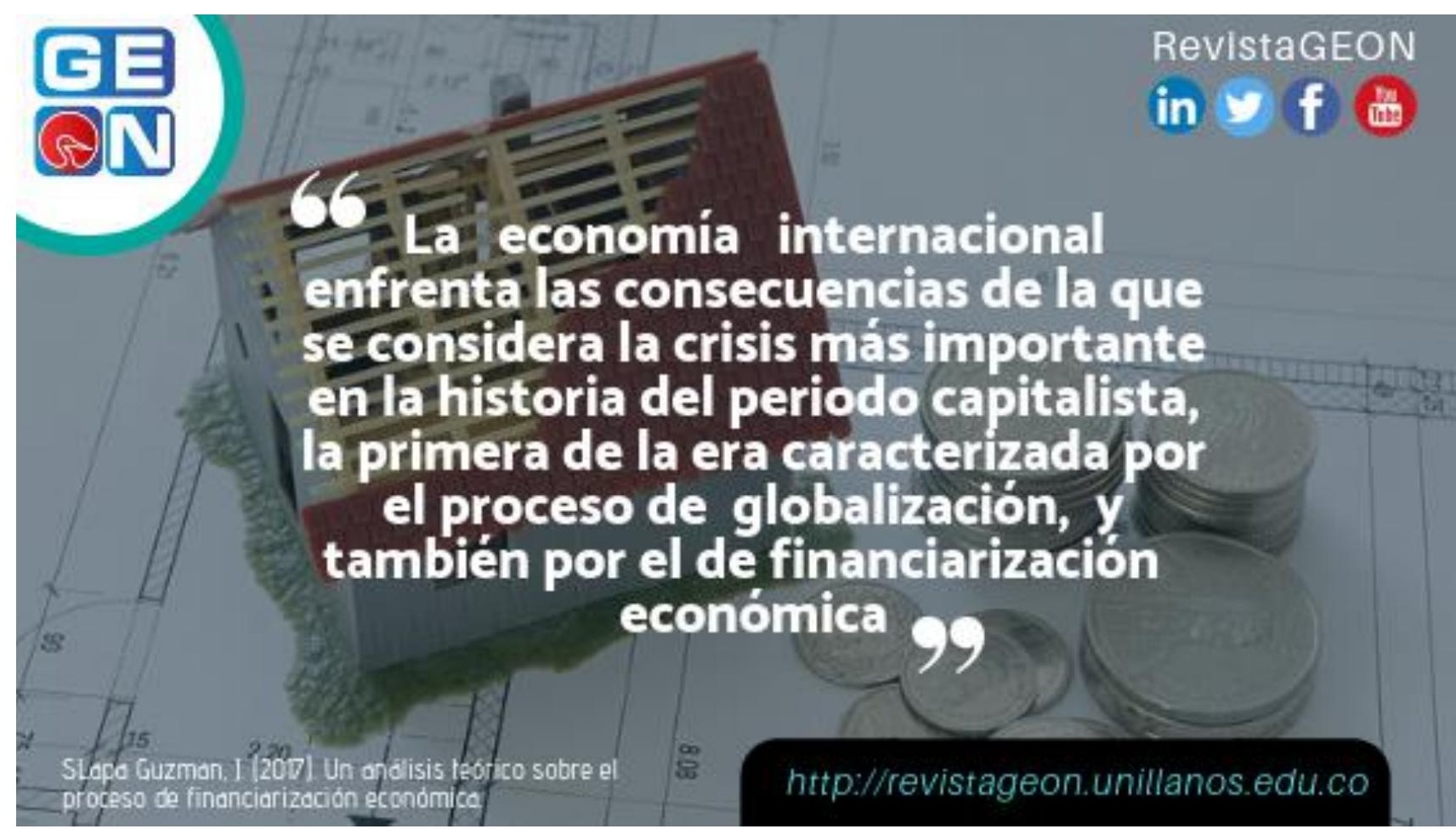




\title{
Un análisis teórico sobre el proceso de financiarización económica por Javier Lapa Guzmán
}

\section{A theoretical analysis on the process of economic financialization by Javier Lapa Guzmán}

Javier Lapa Guzmán

Magister en Economía Financiera Mg Economía Aplicada Universidad Autónoma del Estado de México

javierlapaguzman@hotmail.com
Artículo recibido 2016/08/30 aceptado 2016/11/24

Escrito como parte de ponencia Oral presentada en el IV Congreso Internacional de Investigación en Ciencias Económicas de la

Universidad de los Llanos

\section{Resumen}

El proceso de financiarización económica ha sido definido como una etapa del sistema capitalista en la que las ganancias se persiguen vía canales financieros, y no, a través de los relacionados con la producción y distribución. Este proceso guarda estrecha relación con el notable desarrollo del sector financiero, producto de factores como el progreso tecnológico; la innovación financiera; y la globalización y liberalización de los mercados financieros. Sus efectos no se limitan al ámbito financiero, sino que también repercuten en el productivo, a nivel macro y microeconómico; por lo tanto, su comprensión teórica adquiere relevancia.

Palabras clave: Financiarización, liberalización financiera y sector productivo.

\begin{abstract}
The financialization process has been defined as a stage of the capitalist system in which profits are pursued via financial channels, and not through those related to production and distribution. This process is closely related to the remarkable development of the financial sector, resulting from factors such as technological progress; financial innovation; and globalization and liberalization of financial markets. Its effects are not limited to the financial sector, but also affect the productive sector, macro and micro level; therefore, its theoretical understanding becomes relevant. G0
\end{abstract}

Keywords: Financialization, financial liberalization and productive sector.

\section{Introducción}

Uno de los grandes cambios de la economía internacional durante las últimas décadas es el proceso que diversos autores han denominado como financiarización económica, que de

${ }^{2}$ El análisis mensual de Magdoff y Sweezy (1969), del comportamiento económico global durante treinta años, acuerdo con Magdoff y Sweezy (1969) se trata de una etapa en la que las ganancias se persiguen vía canales financieros, y ya no, a través de los relacionados con la producción y distribución. 2 Este proceso, que ha representado una profunda transformación para las economías capitalistas, tiene su origen en los problemas de acumulación

representa uno de los primeros esfuerzos empíricos por mostrar la existencia del proceso de financiarización. 
real de principios de los setenta. Desde entonces, las actividades financieras se han extendido a nuevas áreas económicas de la vida cotidiana: vivienda, pensiones, becas, consumo, etc; con lo que se han abierto nuevas opciones de inversión y, por lo tanto, para la obtención de ganancias. En el transcurso, son diversos los factores que contribuyeron a dicho crecimiento del sector financiero, por ejemplo, la desregulación de instituciones y mercados financieros; procesos de privatización (tanto de actividades, como de activos); y constantes innovaciones en materia financiera (Lapavitsas, 2009).

A partir de 1980, es claro el aumento de los activos financieros en el mundo; en dicho año representaban un valor de 12 billones de dólares, y para 2006 su valor ya era de 167 billones (véase el cuadro 1 del anexo estadístico). De igual forma, la proporción entre estos y el Producto Bruto Mundial ascendió de $109 \%$ en 1980, a $201 \%$ en $1990,294 \%$ en 2000 y $346 \%$ en 2006 (véase el cuadro 1 del anexo estadístico).

Y en el caso de las economías desarrolladas, dichos activos pasaron de 3.9 billones de dólares en 1995, a 23.6 billones en 2006; mientras que la participación de los mercados emergentes en el total de activos financieros, aumentó de $6 \%$ en 1995, a 14\% en 2006 (McKinsey, 2008). En el cuadro 2 del anexo estadístico, se muestra la proporción de las transacciones financieras respecto al PIB, de 1995 a 2011, para tres países: Estados Unidos, Canadá y México; y en todos los casos el crecimiento de dicho indicador es notable.

Cuadro 1. Activos financieros mundiales*

\begin{tabular}{l|lll}
1990 & 8 & 43 & 19 \\
1995 & 13 & 66 & 20 \\
2005 & 24 & 142 & 17 \\
2006 & 26 & 167 & 16 \\
\hline
\end{tabular}

*Incluyen acciones, títulos de deuda privada y depósitos bancarios. Las cifras representan billones de dólares. Fuente: McKinsey, 2008.

$\mathrm{Y}$ es que, si bien es cierto que el proceso de financiarización tiene su origen en países desarrollados, este ha logrado adquirir una dimensión global, modificando también la dinámica de los países en subdesarrollo. Un ejemplo de ello es el cambio que experimentó en dichos países la relación del sector financiero y el Estado, específicamente en el actuar de los bancos centrales, que adoptaron como principal objetivo, la estabilidad de precios, con el afán de propiciar un ambiente adecuado para la inversión extranjera, que en cierta medida tuvo como destino final el sistema financiero de estos países. 3 De hecho, lo anterior constituye uno de los principales aspectos en que se ha materializado el proceso bajo análisis en tales países; y que de acuerdo a diversos autores representa uno de los factores responsables de la fragilidad financiera, característica de las economías subdesarrolladas durante las últimas décadas. 4

Sin embargo, el notable desarrollo que ha experimentado el sistema financiero, también ha generado cambios en el funcionamiento de las empresas y en diversos aspectos de índole social. En este sentido, se ha visto alterada la composición del financiamiento de las empresas, dado los cambios en el destino del crédito otorgado por la banca comercial, por lo tanto, el

\footnotetext{
${ }^{3}$ Enormes flujos internacionales de capital salieron de los países desarrollados en busca de mercados rentables y se orientaron hacia los países en desarrollo, tan sólo en el año 2000, los flujos de capital privado hacia estos países representaban 74 800 MMD y, para 2007, la cifra ya era de 605000 MDD (FMI, 2008).
}

\footnotetext{
${ }^{4}$ Con el objetivo de atraer flujos de capital extranjero, los gobiernos de los países en subdesarrollo se ven obligados a adoptar una serie de políticas monetarias y fiscales restrictivas, lo cual implica un presupuesto equilibrado, la reducción del gasto fiscal y un compromiso previo de mantener elevados los tipos de interés real; medidas que comprometen la estabilidad económica de los países.
} 
Cuadro 2. Índice de importancia del sector financiero en países seleccionados.

Estados Unidos de Norteamérica

Canadá

México

\begin{tabular}{|c|c|c|c|c|c|c|c|c|c|c|c|c|}
\hline Año & PIB & $\begin{array}{l}\text { Valor de las } \\
\text { transacciones }\end{array}$ & $\%$ & FBKF & PIB & $\begin{array}{l}\text { Valor de las } \\
\text { transacciones }\end{array}$ & $\%$ & FBKF & PIB & $\begin{array}{l}\text { Valor de las } \\
\text { transacciones }\end{array}$ & $\%$ & FBKF \\
\hline 1995 & 7245.8 & 6917.7 & 95 & 1028.2 & 568.63 & 366.3 & 64.43 & 98.4 & 317.06 & 90.7 & 29 & - \\
\hline 1996 & $7,576.1$ & $8,451.7$ & 111.6 & $1,101.5$ & 585.1 & 487.0 & 83.23 & 102.65 & 334.72 & 106.8 & 32 & 57.62 \\
\hline 1997 & $8,083.40$ & $10,730.60$ & 132.70 & $1,173.00$ & 618.3 & 567.6 & 91.80 & 114.5 & 402.8 & 156.6 & 38.90 & 78.7 \\
\hline 1998 & $8,510.7$ & $12,647.9$ & 148.6 & $1,307.8$ & 617.2 & 543.4 & 88.05 & 118.0 & 414.8 & 91.7 & 22.1 & 88.3 \\
\hline 1999 & $9,256.10$ & $16,733.00$ & 180.80 & $1,578.00$ & 644.8 & 789.2 & 122.40 & 125.6 & 446.3 & 154 & 34.50 & 101.6 \\
\hline 2000 & $9,963.10$ & $15,214.60$ & 152.70 & $1,778.20$ & 711.1 & 770.1 & 108.30 & 140.8 & 574.5 & 125.2 & 21.80 & 120.1 \\
\hline 2001 & $10,082.20$ & $13,826.60$ & 137.10 & $1,646.30$ & 705.2 & 611.5 & 86.70 & 139.8 & 617.8 & 126.3 & 20.40 & 121.2 \\
\hline 2002 & $10,480.8$ & $11,055.5$ & 105.5 & - & 737.6 & 570.2 & 77.31 & 145.1 & 592.6 & 103.9 & 17.5 & 111.9 \\
\hline 2003 & $10,480.8$ & $1,143.6$ & 128.6 & $2,025.4$ & 866.8 & 888.7 & 102.52 & 169.3 & 626.1 & 122.5 & 19.6 & 120.9 \\
\hline 2004 & $11,734.3$ & $16,323.5$ & 139.1 & $2,245.2$ & $1,071.9$ & $1,177.5$ & 109.85 & 215.2 & 677.8 & 171.9 & 25.4 & 136.8 \\
\hline 2005 & $12,487.2$ & $17,437.7$ & 139.6 & $2,486.5$ & $1,175.4$ & $1,482.2$ & 126.10 & 240.5 & 777.0 & 239.1 & 30.8 & 150.0 \\
\hline 2006 & $13,246.6$ & $19,569.0$ & 147.7 & $2,594.2$ & $1,236.8$ & $1,700.7$ & 137.51 & 265.6 & 845.6 & 348.3 & 41.2 & 172.5 \\
\hline 2007 & $13,807.6$ & $19,664.5$ & 142.4 & - & $1,436.1$ & $2,186.6$ & 152.26 & - & $1,022.8$ & 397.7 & 38.9 & - \\
\hline 2008 & $14,441.4$ & $11,457.9$ & 79.3 & - & $1,499.6$ & $1,033.4$ & 68.92 & - & $1,088.1$ & 234.1 & 21.5 & - \\
\hline 2009 & $14,119.1$ & $15,077.3$ & 106.8 & - & $1,336.1$ & $1,676.8$ & 125.50 & - & 874.8 & 352.0 & 40.2 & - \\
\hline 2010 & $14,624.2$ & $17,283.5$ & 118.2 & - & $1,563.7$ & $2,170.4$ & 138.80 & - & $1,004.0$ & 454.3 & 45.3 & - \\
\hline 2011 & $15,064.8$ & $15,640.7$ & 103.8 & - & $1,758.7$ & $1,912.1$ & 108.72 & - & $1,185.2$ & 408.7 & 34.5 & - \\
\hline
\end{tabular}

Fuente: Elaboración propia con base en IMF Statistisc Reports (1996-2012).

Es decir, el proceso financiarización presenta múltiples efectos, a nivel macro y microeconómico; además, ante las recientes crisis financieras que han azorado a la economía global, se ha vuelto objeto de un creciente interés. De hecho, dicho proceso es uno de los aspectos centrales para explicar la crisis financiera de 2008 , cuyo origen inmediato se encuentra en el seno del sistema financiero, pero sus raíces son más el proceso de financiarización implica el estudio y comprensión de los efectos derivados de la relación entre el sector financiero y el productivo, que durante las últimas tres décadas se ha visto alterada, debido a la sobredimensión del primero sobre el segundo.

Este proceso constituye uno de los principales temas a debate entre la comunidad académica, sin embargo, los trabajos que lo abordan desde la perspectiva de los países subdesarrollados, son relativamente escasos, y en este sentido México no es la excepción. Y es que la mayoría de los autores interesados en dicho proceso, no solo fijan su atención en países como Estados Unidos, Inglaterra, Francia y Alemania, en donde el sector financiero presenta un mayor desarrollo; sino que generalmente abordan el tema desde la perspectiva del sector financiero, relegando a segundo plano los efectos que implica el proceso de financiarización sobre el sector productivo, es decir, no se profundiza en la relación de ambos sectores.

Por lo tanto, bajo la premisa de que el primer paso para la solución de todo problema es su correcta identificación, a continuación, se describen las principales características del proceso bajo análisis. Lo que contribuirá a la correcta comprensión de su naturaleza, origen y efectos. Para ello, se comienza desde la definición del término, para posteriormente estudiar su origen, así como los principales factores que contribuyeron a su transmisión a escala global. De igual forma, se analiza la naturaleza de la relación entre el sector financiero y el productivo, enfatizando los efectos que el desarrollo del primero implica para el segundo de los sectores involucrados. Y finalmente, se expone una serie de conclusiones y reflexiones sobre el tema.

2. ¿Qué es el proceso de financiarización económica? 
A lo largo de la década pasada, las publicaciones sobre financiarización se han multiplicado, y con ello las descripciones sobre el fenómeno. De acuerdo con Epstein (2005), el término hace referencia a la creciente importancia de los motivos, mercados, actores e instituciones financieras que operan en las economías nacionales e internacionales. Para Aglietta y Bretton (2001), se refiere al hecho de que el mercado de acciones se haya constituido como la fuerza dominante del "nuevo sistema financiero", que a su vez define el régimen de crecimiento. Stockhammer (2004), Crotty (2005), Skott y Ryoo (2008), destacan los efectos macroeconómicos de la financiarización y han utilizado el término para describir los cambios entre las relaciones del mercado financiero y la economía en su conjunto. Por su parte, Arrighi (2003), Harvey (2007) y Lapavitsas (2009) identifican el origen del término, en el proceso de acumulación capitalista, y le dotan de un sentido negativo, dado que consideran se trata de un proceso que guarda estrecha relación con la crisis de sobreacumulación del capitalismo. De hecho, para Lapavitsas (2009), el termino se refiere a una serie de "aspectos dañinos", implícitos en la reciente transformación del sistema financiero.

Así, generalmente se ha utilizado dicho término para describir aquella situación en la que el capitalismo en su conjunto transita de actividades relacionadas con el sector real, hacia actividades propias de la esfera financiera, lo que de acuerdo con Duménil y Lévy, (2004) obedece principalmente al diferencial creciente entre la tasa de rendimiento de las actividades relacionadas con el sector real y las del ámbito financiero, siendo estas últimas las que han ofrecido mayores beneficios en las décadas recientes. En el mismo sentido, Arrighi (1999) describe a la financiarización como un nuevo patrón de acumulación, en el que se prioriza al sector financiero, que, por ende, ha adquirido un creciente poder económico y político, alterando

5 La idea de un "nuevo esquema de funcionamiento macroeconómico", ha sido mencionada por otros autores que la han nombrado de diferentes maneras: régimen de crecimiento dirigido por las finanzas (Boyer, 2000), economía mundial financiarizada (Epstein, 2005), régimen de acumulación su relación con los demás sectores económicos. Y es precisamente, dicha situación la que de acuerdo a Ponssard (2002), ha propiciado una serie de cambios en la gestión empresarial, que pueden resumirse en el hecho de haber adoptado la lógica financiera como directriz.

Así, el proceso de financiarización se presenta como un tema complejo, que abarca distintos aspectos de la actividad económica; por lo que resulta pertinente abordarlo desde dos niveles, el primero y más general, para referirse a la sobredimensión de la esfera financiera respecto a la productiva, y el segundo, para señalar los cambios que genera en las unidades cuya actividad no es financiera. Es decir, se trata de un proceso, con el cual emerge la primacía de las finanzas en la dinámica macroeconómica y en las prioridades de empresas, hogares y administraciones públicas. Dando inicio a un nuevo patrón de acumulación, en el que los beneficios se obtienen principalmente a través de los canales financieros, y no, de los relacionados con el comercio y la producción de mercancías, lo que genera múltiples efectos económicos.5 De acuerdo con Orhangazi (2008) tales efectos, que pueden ser de carácter cualitativo y cuantitativo, operan mediante tres vías: modificando la estructura y operación de los mercados financieros; alterando el comportamiento de las empresas no financieras; e influyendo en la política económica de los países.

Dadas las características propias del tema, es comprensible que este haya sido abordado desde distintos enfoques. Para los autores poskeynesianos, el proceso de financiarización es exclusivo de la macroeconomía, siempre subordinado al crecimiento económico, la hipótesis de la fragilidad financiera de Minsky (1986) es un buen ejemplo de ello. Resulta interesante la forma en que han identificado los vínculos entre dicho proceso y la economía real, dado que han centrado su análisis en la variación

financiarizado (Chesnais, 2003), capitalismo accionarial (Plihon, 2004), capitalismo financiero (Batsch, 2002), en todos los casos se busca señalar la nueva dinámica de la economía mundial. 
del nivel salarial (Arestis, 2001; Eatwell, 2000; Kregel, 2007; entre otros).

Por su parte, algunos autores regulacionistas, consideran a la liberalización financiera, como el motor institucional de los cambios más importantes del régimen de crecimiento (Aglietta, 2005; Rebeiroux, 2003; Orlean, 1999; entre otros). Sin embargo, han relegado a segundo plano, o al menos no han puesto el suficiente interés, en definir las repercusiones del proceso sobre la lógica empresarial, centrándose específicamente en los efectos de índole macroeconómico e institucional. A diferencia, de los autores provenientes de la economía de la empresa (Coutrot, 1998; Hancké, 2006, Sauviat, 2001; entre otros), que han profundizado su análisis en los vínculos entre el proceso de financiarización y los cambios acontecidos en la gestión empresarial, enfatizando que actualmente, esta se encamina a garantizar el crecimiento de su valor accionarial y no su productividad.

Por supuesto que el tema también ha generado gran interés entre autores de carácter Marxista (Husson, 2008; Dúmenil y Levy, 2004; entre otros), que han puesto su atención en la naturaleza y el origen del proceso, al que consideran como la respuesta del capital ante la caída de la tasa de ganancia, en el marco de la crisis de acumulación, iniciada en los años setenta.6 Además, destacan el efecto que dicho proceso ha tenido sobre el salario, al relegarlo a variable de ajuste del sistema, lo que explica el fuerte retroceso del que ha sido objeto. En el mismo sentido autores como Black, Gospel y Pendleton (2005) han descrito las transformaciones que ha sufrido la organización laboral, principalmente, la dinámica de los sindicatos. Y recientemente, han comenzado a desarrollarse líneas de investigación relacionadas con los efectos secundarios del proceso, por ejemplo, el papel del crédito como sustituto del salario.

${ }^{6}$ Ante el pobre desempeño de la tasa de crecimiento de la economía real, el capitalismo se ha vuelto cada vez más dependiente de las ganancias provenientes de las actividades
A pesar de la diversidad de enfoques desde los que ha sido analizado el proceso de financiarización, es posible identificar algunas ideas generales, presentes en la mayoría de los trabajos hasta ahora citados $y$ que hacen referencia a las características esenciales de este; por ejemplo: la primera de ellas, se refiere a la concepción y origen del mismo, existe cierto acuerdo sobre el hecho de considerarlo como resultado de la nueva era de cambios macroeconómicos, iniciada durante la primera crisis del petróleo en 1973, que marcó el fin del largo auge de posguerra; desde entonces, la acumulación real ha tenido un aumento precario, a diferencia del sector financiero que ha crecido de manera constante en términos de empleo, utilidades y tamaño de las instituciones y los mercados; lo que en gran medida obedece a que se han llevado a cabo procesos de desregulación, cambio tecnológico e institucional, innovación y expansión. Lo anterior, se ha reflejado en una mayor presencia de actividades relacionadas con el sector financiero en la dinámica económica de los países, no sólo desarrollados, sino también en los subdesarrollados.

La segunda, se refiere al incremento en la adquisición de activos financieros, principalmente de corto plazo, por parte de empresas no financieras. Lo que de acuerdo con (Epstein, 2005), obedece a la búsqueda de nuevos canales para la obtención de mayores ganancias, en periodos de tiempo cada vez más cortos. A lo que ha contribuido la revolución tecnológica en el campo del procesamiento de la información y las telecomunicaciones, dado sus repercusiones en la esfera de la circulación. Por otro lado, autores como Eatwell (2000) consideran que dicha lógica también ha permeado en la actividad bancaria, dado que los bancos han visto alterada su función integradora, de recopilar información, y transferir recursos mediante la sociedad, con la intención de promover la inversión productiva; principalmente, debido a los avances en el campo de la ingeniería financiera. Lo que, a su vez, también ha modificado los canales tradicionales

financieras, para poder incrementar el capital (Dúmenil y Levy, 2004). 
de financiamiento y obtención de ganancias de las empresas no financieras.

Lo anterior, en el marco de profundos cambios institucionales y políticos, entre los que destaca la desregulación del sistema financiero, $\mathrm{y}$ el reemplazo del keynesianismo, característico del largo auge de posguerra; por el modelo neoliberal de crecimiento. A partir de ello, el sector financiero, no solo presenta un notable crecimiento, sino que de acuerdo con autores como Sweezy (1994), Foster (2007) y Stockhammer (2009), comenzó un "efecto sustitución" de la inversión productiva, por la de índole financiera; gestándose una relación inversa entre el sector financiero y el real; que constituye la tercera de las ideas generales, y a la que se atribuye gran parte de los cambios recientes en el panorama económico internacional.

\section{Génesis y consolidación del proceso.}

La crisis de los años setenta se pareció desde muchos puntos de vista a la de 1930; no se redujo a un incidente pasajero, se trató de un fenómeno profundo, con efectos de largo plazo, es decir, una crisis estructural, cuyos primeros signos aparecieron en Estados Unidos a finales de los años sesenta. Dicha crisis se materializó en una serie de efectos negativos, por ejemplo: el crecimiento y el progreso técnico resultaron afectados; se registraron índices de inflación "récord", no sólo en la economía norteamericana, sino también en otros países desarrollados; los salarios quedaron estancados; se gestó una gran ola de desocupación; y la tasa de ganancia se derrumbó. De hecho, para Epstein (2005) es precisamente, en los efectos que dicha crisis generó sobre el nivel de rentabilidad, donde debe buscarse el origen del proceso de financiarización.

Al respecto, son diversas las explicaciones teóricas, sin embargo, es posible agruparlas en tres principales teorías: la primera, lo considera como una etapa, de las que constituyen una onda larga; responsables del comportamiento cíclico de la Economía, es decir, no se trata de un "capitalismo particular", sino que forma parte de su comportamiento "natural". En esto último,
Arrighi (1994, 2003, 2005) difiere, ya que para este autor se trata de la fase que marca el final de la hegemonía económica en turno, y no sólo de un periodo de auge; argumenta que las condiciones económicas que precedieron a la caída de los dos últimos países hegemónicos, comienzan a configurarse nuevamente, por ejemplo, cambios en el funcionamiento de la economía real (negativos), reducción del poder de la nación hegemónica y un reclamo generalizado de la sociedad que padece los costos de la sobredimensión de la esfera financiera.

La segunda teoría, considera que el proceso de financiarización es resultado de las medidas de política económica promovidas por el paradigma neoliberal, es decir, se trata de una variante perversa del capitalismo, que fue la respuesta al estancamiento del sector productivo, que amenazaba las ganancias del capitalista. De acuerdo con diversos autores (Crotty, 2005; Sweezy, 1997; Amin, 1996), este proceso explica en gran medida las características del modelo neoliberal: lento crecimiento de los niveles de empleo; endeudamiento creciente de los países subdesarrollados y de la sociedad en general; política fiscal restrictiva, derivada de la promoción por parte de los organismos internacionales de programas de austeridad; y bajos niveles de crecimiento económico.

Y finalmente, está la teoría, para la cual, el proceso de financiarización es resultado de la evolución de la esfera financiera. Por lo tanto, es resultado de la gran masa de recursos que circula en los mercados financieros en busca de mayores rendimientos. Lo que ha sido posible, gracias a la globalización financiera que se ha desarrollado de forma vertiginosa en los últimos treinta años, y cuyos efectos no se han limitado al ámbito financiero, sino que también han modificado la dinámica del sector real. Principalmente, porque se ha promovido una mayor participación de las empresas no financieras en actividades de carácter financiero, con lo que se ha alterado la lógica de estas, que han dejado de comportarse como unidades de producción, y han adoptado un comportamiento más parecido al de los agentes financieros. De esta manera, la financiarización es causa y no consecuencia del periodo de baja 
acumulación que siguió a los años de posguerra, dado los efectos negativos que ha significado para la inversión real (Stockhammer, 2004).7

Sin embargo, en lo referente al origen geográfico del proceso en cuestión, la mayoría de los autores interesados en el tema, lo ubican en las economías desarrolladas, específicamente, en la estadounidense. Por lo tanto, consideran que la revisión histórica debe partir del periodo inmediato posterior a la crisis de 1929 , dado que en dicho periodo se llevaron a cabo una serie de cambios en el ámbito financiero, encaminados a incrementar su regulación; por ejemplo, a través del Acta Bancaria de 1933, se creó la Corporación Federal de Seguro de Depósitos (FDIC, por sus siglas en inglés) con el objetivo de contrarrestar pánicos bancarios; se separó a las empresas de valores, de los bancos comerciales; y se prohibió a estos últimos garantizar créditos con fines especulativos, así como el pago de intereses con depósitos. Sin embargo, de acuerdo con Wray (2007) las instituciones financieras respondieron a cada una de estas medidas regulatorias, innovando, estableciendo nuevas prácticas e instrumentos que pudieran evadir dicho marco regulatorio; y con el tiempo, la tendencia hacia comportamientos de índole especulativa no solo fue creciente, sino que se volvió prácticamente imposible de atenuar.

En 1944, la conferencia de Bretton Woods marcó el fín del nacionalismo económico, e impuso la noción de mercados abiertos, además de dar origen al Fondo Monetario Internacional (FMI) y al Banco Internacional de Reconstrucción y Fomento (BIRF); lo que dio inicio a una serie de cambios en la relación de los países y el sistema financiero mundial, bajo la lógica de permitir una interacción más laxa entre ambos. Sin embargo, la profundización de dichos cambios, se llevó a cabo veinte años después, es decir, tras la costosa crisis de los países

\footnotetext{
${ }^{7}$ Para mayor profundización en la discusión sobre la naturaleza del proceso de financiarización, se recomienda la revisión de las siguientes fuentes: Orhangazi, 2008; Krippner, 2005; Stockhammer, 2004; Arrighi, 1999 y Froud, 2006.
}

8 Huffschmid (2002) denomina a las reformas estructurales como "contrarreformas neoliberales", con la desarrollados durante la década de los setenta, y ante la cual, estos optaron por dejar de lado las políticas de corte keynesiano; lo que supuso una transformación estructural, que no sólo modificó el modelo económico imperante en dichos países, sino que alteró el contexto internacional.

En el caso de la economía estadounidense, dicha crisis implicó una serie de efectos negativos, tanto en el ámbito productivo, como en el financiero; en el primero, redujo los beneficios empresariales, y por ende los dividendos entre accionistas, mientras que, en el segundo, desató un proceso inflacionario que menguó el valor de las inversiones financieras. Ante tal situación, el sector empresarial decidió parapetarse tras la ideología neoliberal, que, ante la incapacidad de las políticas de corte keynesiano para solucionar el problema, se presentaba como la mejor opción (Duménil y Levy, 2005). Es decir, en cierta medida, como resultado de la presión ejercida por los sectores industrial y financiero, se llevaron a cabo una serie de cambios en términos de política económica, así como una reestructuración de la dinámica económica y de las instituciones; gestándose la llamada "revolución conservadora", que contó con el apoyo del presidente norteamericano Ronald Reagan, la primera ministra británica Margaret Thatcher y el canciller alemán Helmut Kohl.

Dicha "revolución" estuvo compuesta por una serie de políticas que Huffschmid (2002) denomina como "contrarreformas neoliberales", y cuyo principal objetivo fue revertir la tendencia de la rentabilidad, a través de recomponer las condiciones propicias para ello. Entre dichas medidas, se encuentran: una generalizada privatización, liberalización financiera y apertura comercial irrestricta de las distintas economías. 8

En el ámbito financiero, la "reinterpretación" de la Ley Glass-Steagall en

intención de mostrar que la ofensiva del capital es precisamente contra aquellas reformas conquistadas por la clase trabajadora al finalizar la II Guerra Mundial (pleno empleo, salarios crecientes, empleos estables, seguridad social, pensiones públicas, servicios sociales públicos, etc.). 
1986, representó la consumación de los distintos esfuerzos por desregular las actividades en dicho sector. Por ejemplo, se les permitió a los bancos comerciales generar el $5 \%$ de sus ingresos brutos en operaciones de banca de inversión; llevar a cabo ciertas actividades de compra-venta de papel comercial, bonos municipales y valores respaldados por hipotecas; y posteriormente se les autorizó vender acciones y emisiones de deuda, con límites cada vez más holgados (Davidson, 2009). Finalmente, en 1999 con el apoyo de la mayoría de la cúpula política estadounidense la Ley Glass-Steagall fue derogada, y en cambio, se aprobó la denominada Gramm-Leach-Bliley.

Esta nueva reglamentación permitió que bancos de cualquier tamaño pudieran involucrarse en una gama más amplia de actividades financieras, ofreciendo productos $\mathrm{y}$ servicios sin restricciones regulatorias. Los bancos comerciales expandieron su radio de actividades en mercados restringidos a los bancos de inversión; y estos a su vez, se involucraron en actividades reservadas a bancos comerciales. Junto a la serie de modificaciones hechas a la estructura institucional regulatoria, se llevaron a cabo dos cambios importantes referentes a los bancos centrales: la autonomización de estas entidades del estado, y su concentración, en muchos casos exclusiva, en el control de la inflación.

El proceso de liberalización y desregulación de los mercados financieros internacionales, significó la eliminación de las restricciones que se habían impuesto al desarrollo especulativo y cuasi autónomo de las finanzas durante el periodo keynesiano; lo que propició una mayor demanda de productos financieros, como mecanismo de manutención y extensión de ganancias, obligando a las instituciones financieras norteamericanas a emitir una serie de nuevos instrumentos financieros: futuros, opciones, derivados, fondos de cobertura, etc. 9

9 El objetivo inicial de la profusión de instrumentos financieros fue asegurar los riesgos cambiarios y financieros, pero luego se convirtieron en fuente de especulación financiera (Salama, 1998).
De esta manera, la liberalización financiera constituyó un proceso indispensable para el de financiarización, y a su vez, éste afianzó al primero, es decir, se trata de procesos complementarios.

Las reformas políticas, económicas y monetarias llevadas a cabo durante este periodo, configuraron paulatinamente una de las problemáticas que caracterizaría a la economía estadounidense durante las décadas siguientes: especulación financiera; que, aunada al estancamiento económico en los primeros años del siglo XXI, es responsable de la crisis financiera de 2008. Y es que, en tal situación, las empresas se tornaron cada vez más dependientes del sector financiero, en términos de ganancias, es decir, el desarrollo de dicho sector terminó por gestar "burbujas especulativas", uno de los mayores problemas económicos en la actualidad.10

Así, de acuerdo con Sweezy (1989), es posible describir la evolución de la economía estadounidense a partir de las denominadas "tres tendencias implícitas del capitalismo moderno": la primera se refiere a la aparición de empresas con capacidad de control sobre el mercado, mismo que se traduce en poder financiero, y que a su vez les permite obtener mayores beneficios, gestándose un proceso de financiarización, que constituye la segunda de dichas tendencias. Lo anterior reduce la inversión destinada hacia actividades realmente productivas, con lo que se limita la acumulación de capital, y con ello se frena el crecimiento y el desarrollo económico, configurándose la última de las tendencias.

Y es que de acuerdo con Dúmenil y Levy (2005), sin importar el grado de expansión del proceso de financiarización, éste no ha sido capaz de resolver el estancamiento del sector real estadounidense. Y si bien es cierto que dicho proceso fue responsable en cierta medida de la

${ }^{10}$ Desde un enfoque postkeynesiano el comportamiento de los mercados financieros es irracional y presenta una serie de vicios en su funcionamiento, como la incertidumbre que impera en ellos y la fragilidad constante en la que actúan los inversionistas, dichos vicios se ven potenciados cuando se transita de estructuras financieras estables a estructuras desreguladas. 
relativa recuperación económica en la década de los noventa, también es cierto que resultó insuficiente, si se considera que no pudo igualar la tasa de acumulación y crecimiento alcanzada durante el periodo de posguerra, y con ello dar inicio a un periodo largo de prosperidad sostenida.

Así, a partir de las distintas reformas señaladas se fue configurando el notable crecimiento del sector financiero, sin embargo, su consolidación obedeció principalmente a la globalización de los mercados de dinero y capitales, que tomó impulso durante la década de los ochenta, debido a diversos factores, entre los que destacan: la acumulación de grandes masas de ahorro de los países exportadores de petróleo y $\mathrm{su}$ reciclaje en activos financieros, el crecimiento de los fondos de pensiones de las economías desarrolladas; la consolidación de grandes corporaciones privadas, industriales y de servicios, cuyas cajas de tesorería engrosaron de forma notable; la desregulación de los principales mercados financieros del mundo, que permitió a los llamados inversionistas institucionales (sociedades mutualistas, bancos de inversión y comerciales, corporaciones privadas, compañías de seguros) operar fuera de los segmentos en los que anteriormente se dividían los mercados, en función de la especialización de actividades; la liberación de los movimientos de capital en la mayoría de los países del mundo, en particular en los llamados mercados emergentes, y la revolución tecnológica en materia de telecomunicaciones, sistemas de cómputo y, en general, las llamadas "tecnologías de la información".

$\mathrm{Y}$ es que a partir del avance de las redes electrónicas y los sistemas de procesamiento de la información fue posible la integración horizontal de los mercados bursátiles que operan de manera ininterrumpida y se entrelazan automáticamente. Además, se desarrollaron y perfeccionaron nuevos instrumentos bursátiles, más allá de los tradicionales bonos, acciones y el papel comercial de corto plazo, que permitieron la integración vertical de los mercados (el presente con el futuro). Y es que, si bien es cierto que desde la década de los setenta los banqueros y agentes de bolsa habían desarrollado nuevas modalidades de operaciones de futuro, opciones y derivados sobre la deuda gubernamental y corporativa, incluida la flotación de bonos respaldados con el flujo de pago de las deudas hipotecarias; la maquinaria para la invención de fórmulas que permitieran dispersar riesgos tuvo su auge durante la década de los noventa y los primeros años del siglo XXI.

Además, debe considerarse la abrupta expansión del crédito que tuvo lugar a partir de la década de los noventa, resultado de una política de bajas tasas de interés, que de acuerdo con Lapavitsas (2011) guarda estrecha relación con la crisis de 2007-08; ya que implicó una serie modificaciones para la banca comercial, por ejemplo, su principal fuente de utilidades ya no se limitó al margen financiero, sino que las comisiones cobradas por el otorgamiento de créditos y los honorarios por la venta de estos a distintas entidades financieras, adquirieron una creciente importancia. A este cambio de modelo de operación bancaria, le acompañaron nuevos agentes institucionales, instrumentos y mercados, todos operando bajo un esquema de escasa o nula regulación; situación que a la postre permitiría una serie de actividades de alto riesgo, por ejemplo, instituciones financieras que toman dinero prestado a corto plazo en mercados revolventes, se apalancan significativamente y prestan e invierten a largo plazo en activos ilíquidos; entre otras actividades de elevada incertidumbre.

En resumen, la globalización financiera ha sido la tónica del desarrollo del sistema económico internacional durante las últimas décadas; impulsada por el progreso tecnológico en materia de información, la constante innovación financiera y la liberalización casi universal de los mercados de dinero y capital. Sin embargo, con el tiempo se han configurado una serie problemas en el sistema financiero internacional, por ejemplo, la concentración de las operaciones en ciertas empresas, lo que termina por otorgarle a sus decisiones de inversión, un mayor grado de relevancia para el sistema financiero en su conjunto, con lo que el riesgo de dichas decisiones ya no sólo recae en los accionistas de la empresa en cuestión, sino que sus efectos adquieren un alcance mayor; por lo 
que a la inestabilidad característica del sistema, se suma un riesgo sistémico, que constituye uno de los aspectos del sistema financiero que más interés ha generado entre los estudiosos del tema.

\section{La relación entre el sector financiero y el} productivo.

Como ya se ha dicho, durante las últimas décadas, se ha llevado a cabo una serie de reformas en el ámbito financiero, entre las que destacan: la apertura al capital extranjero, la privatización progresiva de las coberturas sociales, la desregulación de los mercados, y la internacionalización del capital financiero.11 Los efectos derivados de dichas reformas, han dado inicio a un debate sobre la naturaleza de la relación entre el sector financiero y el real, al grado de representar actualmente uno de los principales temas de discusión económica.

En este sentido, es posible identificar tres principales posturas: la primera, considera que el desarrollo del sector financiero tiene un efecto positivo sobre el crecimiento económico, por lo tanto, un proceso de liberalización financiera, no sólo implica la expansión de dicho sector, sino que conlleva una mejor asignación de los recursos entre las diferentes ramas económicas, privilegiando los proyectos de inversión más rentables y con mejores perspectivas de éxito. Esto, porque se supone que los mercados financieros llevan a cabo una evaluación de rentabilidad de los proyectos económicos, por lo que el nivel de riesgo se reduce considerablemente. Por lo tanto, no solo, no existe espacio para los efectos desestabilizadores

\footnotetext{
${ }^{11}$ Resulta pertinente resaltar el papel que desempeñaron los organismos internacionales como el Fondo Monetario Internacional (FMI) y el Banco Mundial (BM) en la consecución de las reformas señaladas. En el caso de los países subdesarrollados, también las instituciones financieras privadas tuvieron una injerencia considerable al respecto; primero, porque permitieron a dichos países refinanciar su deuda externa en términos y condiciones más favorables al capital privado; y segundo, porque promovieron la liberalización de la cuenta de capital, con lo que dio inicio la afluencia de capitales a los países subdesarrollados. Lo anterior quedó plasmado en el Paln Brady.

${ }^{12}$ Mckinon y Shaw son los autores de la llamada "Teoría de la represión financiera", según la cual; restringir el
}

de la especulación; sino que los flujos de capital propician una redistribución a escala global de la inversión, dado que esta se dirige hacia los países que ofrecen mayores utilidades, contrario a lo que sucede si se implementan restricciones nacionales a los movimientos de capitales, ya que se limita y distorsiona el desarrollo financiero, obstaculizando la función primordial de dicho sector: canalizar el ahorro, hacia las empresas y gobiernos que necesiten financiamiento, favoreciendo así, la inversión productiva; lo que a su vez se traducirá en una mayor tasa de inversión, de crecimiento y de generación de empleo (Goldsmith, 1969; McKinnon, 1973; Shaw, 1973; Odedokun, 1996; Levine, 2004).12

Es decir, la reducción del costo de capital y el incremento de la eficiencia en la asignación de los recursos constituyen los principales canales a través de los cuales, el desarrollo del sector financiero repercute sobre el real de manera positiva; lo que a su vez, se espera promueva el crecimiento económico.13 Sin embargo, autores como Stockhammer (2009) y Orhangazi (2008), consideran que la evidencia empírica hasta ahora, no valida que dicha relación positiva entre sectores se haya llevado a cabo. De acuerdo con estos autores, si bien es cierto que el sector financiero desempeña un papel esencial como promotor del crecimiento económico; el abrupto desarrollo de éste durante las últimas décadas, ha terminado por desvirtuar su función como fuente de financiamiento para las actividades productivas, al grado de invertir la relación entre sectores, originalmente positiva. De esta manera se configura la segunda de las posturas teóricas sobre la naturaleza de la relación entre ambos sectores; es decir, se considera que dicha relación

funcionamiento del sistema financiero tiene un efecto negativo sobre la economía, debido a que se genera una ineficiente asignación de los recursos.

${ }^{13}$ Se debe tener en cuenta que el desarrollo del sector financiero queda sujeto al proceso de liberalización financiera, que deberá llevarse a cabo considerando las condiciones de índole económica, social, financiera y gubernamental, de cada país; ya que esto determinará el éxito o fracaso de dicho proceso. Por ejemplo, los países con un sector bancario desarrollado cuentan con mejores condiciones para generar proyectos de inversión que puedan impulsar el crecimiento económico, debido a la mayor disponibilidad de recursos financieros $(\mathrm{Xu}, 2000)$. 
es de carácter negativo, lo que explicaría en cierta medida el riesgo sistémico y los problemas de especulación que han caracterizado a la economía mundial durante los últimos años.

Esta postura tiene implícita la idea de que la inversión financiera termina por sustituir a la productiva, dado que los recursos disponibles de las empresas no financieras pueden ser invertidos en activos financieros o reales, dependiendo de la rentabilidad ofrecida por cada uno de ellos. Así, en periodos en los que los activos financieros ofrezcan tasas de rentabilidad superiores a las de los proyectos de inversión productiva, una mayor cantidad de recursos serán invertidos bajo la forma de capital financiero; limitando los disponibles para inversiones productivas. Por lo tanto, una mayor compenetración entre sectores, no necesariamente debe traducirse en efectos positivos para la actividad productiva, de hecho, si la lógica prevaleciente es la de la rentabilidad máxima, probablemente los capitales fluyan a la esfera financiera, lo que de acuerdo con Krippner (2005) explica que el peso de las finanzas en la lógica empresarial sea cada vez mayor, hasta el punto de volverse dominante, y es entonces, cuando el desarrollo del sector financiero condiciona el del productivo.

Lo anterior, según Orhangazi (2008) obedece en cierta medida al funcionamiento de los mercados financieros, cuya perfección parece basarse más en aspectos teóricos e ideológicos, que en hechos reales.14 En este sentido, Stiglitz (2002) considera que un proceso de liberalización financiera incrementa la volatilidad de los mercados financieros, lo que a su vez genera un mayor riesgo para la inversión; con efectos negativos sobre la tasa de crecimiento de la economía real. Además, según el autor, debe considerarse el hecho de que, una vez iniciado un periodo de crisis o recesión financiera, la inversión en investigación, infraestructura y la destinada a incrementar la productividad,

14 Entre los aspectos que impiden el "correcto" funcionamiento de los mercados se encuentran: la información asimétrica y la competencia imperfecta (VanWinjbergen, 1983).

15 Además, para Levine (1995), el argumento de que la recuperación que presentan la mayoría de los países en el periodo inmediatamente se reduce, limitando aún más el crecimiento de largo plazo.15

De acuerdo a esta segunda postura, para que un proceso de liberalización financiera se traduzca en un menor costo del capital para las empresas; en una mejor eficiencia de los mercados financieros; y por ende en mayores tasas de crecimiento económico, es necesario que esté acompañado de crecientes flujos de capital extranjero; para lo cual, los países deben implementar una serie de medidas que atentan contra su estabilidad macroeconómica; por ejemplo: una tasa de interés por arriba de lo recomendable y un tipo de cambio fijo. Además, se debe considerar la composición de dichos flujos; ya que, si predominan los de largo plazo, dirigidos a la inversión real; en efecto contribuirán al crecimiento del sector real, pero si, por el contrario, están constituidos por capitales de corto plazo, el efecto será el opuesto, ya que estos son responsables de generar períodos de gran inestabilidad, lo que termina por afectar negativamente a la inversión productiva.

Finalmente, la tercera de las posturas, sostiene que no existe relación alguna entre el desarrollo de ambos sectores (Robinson, 1952 y Lucas, 1988). Sin embargo, ante los diversos vínculos señalados, la existencia de dicha relación ha dejado de cuestionarse. De hecho, se ha establecido que su importancia es tal, que determina la evolución de ambos sectores. El debate ahora se centra en determinar el sentido y carácter de la relación, así como en los efectos que se deriven de ella. Ya que evidentemente el sector financiero ha experimentado cambios a raíz del proceso de globalización financiera, sin embargo, también el sector productivo presenta modificaciones; derivadas de su relación con el primero; y es en ellas en las que se debe profundizar.

inmediato siguiente a liberalizar sus mercados, probablemente obedezca en gran medida a la fase natural del ciclo económico y no tanto al proceso de liberalización. Es decir, si no se considera lo anterior se corre el riesgo de sobrevalorar el efecto de dicho proceso. 


\section{Efectos macro y microeconómicos.}

Como resultado de los recientes periodos de crisis financiera, se ha generado una serie de interrogantes sobre los beneficios de la nueva configuración financiera, asociada al modelo neoliberal de crecimiento; por ejemplo: si el desarrollo de las actividades no financieras, presenta las mismas características que el de las financieras; si se ha incrementado la participación de las empresas no financieras en actividades financieras; o si el desarrollo de las finanzas ha significado un incremento de la inversión productiva; entre otras.

Las respuestas a dichas interrogantes pueden ser abordadas desde dos enfoques; el primero, propio de los partidarios del modelo neoliberal, que enfatizan las ventajas derivadas del desarrollo de las actividades financieras; señalan que la principal función del sector financiero, es precisamente dotar de financiamiento a la economía en su conjunto, y para ello resulta necesario que los recursos disponibles no permanezcan estáticos, sino al contrario, gocen de completa autonomía, ya que solo de esa manera, podrán fluir a los agentes financieros, encargados de redistribuirlos de manera eficiente entre las diversas opciones de inversión. Por lo tanto, bajo esta lógica, el desarrollo del sector financiero resulta benéfico para la economía en general.

Por otro lado, el segundo de los enfoques es diametralmente opuesto, ya que señala una serie de elementos que ponen en riesgo la materialización del efecto anteriormente señalado, por ejemplo: elevadas tasas de interés cobradas por los bancos, o la obtención de grandes dividendos vía actividades de índole especulativa. Además, autores como Duménil y Levy (2007), sostienen que el desarrollo de la actividad financiera es potencialmente capaz de desviar la inversión productiva, beneficiando únicamente a la inversión de tipo financiera. Para dichos autores, la diferencia entre las tasas de rendimiento ofrecidas por cada sector constituye la base del argumento planteado.

Bajo la lógica del primer enfoque, impulsar un proceso de apertura financiera adquiere mucho sentido, ya que se generarían diversos impactos positivos, por ejemplo, mejoraría la eficiencia del flujo de recursos, de los países con ahorro, hacia los que presentan escasez de capital, pero que a su vez, cuentan con atractivas oportunidades de inversión; lo que no sólo resultaría rentable, sino que también abonaría a la reducción de los riesgos, en los que incurren los inversionistas, nacionales y extranjeros; debido a que de esta manera diversificarían sus activos; y claro, también los países receptores de dichos recursos, se verían beneficiados, dado que gozarían de capital disponible para invertir, lo que les permitiría entre otras cuestiones, mejorar el resultado de su balanza de pagos, en el entendido de que aumentarían sus exportaciones, como resultado del financiamiento al sector productivo nacional. Además, el sistema financiero de estos países resultaría beneficiado debido a la sana competencia que se generaría entre las instituciones financieras nacionales y las extranjeras; y también, a la exposición al mercado financiero internacional (Levine, 1996 y Poret, 2001).

Sin embargo, de acuerdo con Medialdea (2003), lo anterior implica una serie costos para estos países, en términos de autonomía para la formulación de su política económica; limitándoles su margen de acción y obligándolos en cierto grado a llevar a cabo medidas que no siempre resultan benéficas a mediano y largo plazo. Desde la óptica de los organismos internacionales dicha restricción representa un beneficio para la economía global, ya que propicia cierta homogeneización en términos de política económica, con lo que se reduce el riesgo de que los países subdesarrollados lleven a cabo medidas irresponsables, que atenten contra la estabilidad económica del orbe. Para Kremp (2008), dicha homogeneización obligó a los países subdesarrollados a garantizar rendimientos financieros, difíciles de sostener, lo que terminó comprometiendo la estabilidad de su sistema financiero, dado que se propició una serie de nuevas estrategias que permitieran cumplir con los rendimientos prometidos, y se orilló a las sociedades no financieras, a llevar a cabo cambios en sus opciones de inversión y financiamiento; 
que pasaron a ser altamente líquidas y supeditadas a la lógica de obtención de rendimientos a corto plazo.

Así, si bien es cierto que tras la implementación de las distintas reformas recomendadas por los organismos internacionales, principalmente el Fondo Monetario Internacional (FMI), los países subdesarrollados recibieron considerables flujos de capital, sin embargo, de acuerdo con Medialdea (2003), las condiciones del proceso y las características de tales flujos, fueron los principales responsables de la crisis de las distintas crisis que experimentaron esos países durante la última década del siglo pasado (México en 1994; el sureste asiático en 1996-1997; Rusia en 1998; Brasil en 1998-1999; Turquía en 2000; y Argentina en 2001-2002).

Para Stockhammer (2009), la lógica antes descrita también explica en cierta medida la crisis estadounidense de 2008, que constituye la última de las dudas sobre los beneficios reales del proceso de liberalización financiera, y, por ende, del de financiarización económica, en términos de crecimiento y estabilidad macroeconómica. Por lo tanto, resulta pertinente analizar con atención, los cambios derivados de ambos procesos, tanto a nivel macro, como microeconómico.

A nivel macroeconómico, son diversos los efectos derivados de dicho proceso, por ejemplo, instrumentos financieros cada vez más opacos, con estructuras complejas, diseñadas para ocultar su riesgo implícito; un proceso de concentración de las operaciones, en determinadas organizaciones, lo que dota de gran influencia económica a sus decisiones; la aparición de inversionistas institucionales que se han convertido en protagonistas de los mercados financieros; la consolidación del riesgo sistémico en el funcionamiento del sistema financiero internacional; mecanismos de supervisión inadecuados, en parte por su incomprensión de los entes supervisados; y finalmente, como

\footnotetext{
${ }^{16}$ Para Correa y Girón (2004), la participación en los mercados financieros no solo es de corto plazo, sino que es oportunista, en el sentido de que únicamente se busca participar cuando los mercados se encuentran en auge, y se intenta
}

resultado de lo anterior, la conformación de un conjunto de entidades, mercados y prácticas, alejadas de cualquier tipo de regulación (Palley, 2008).

De esta manera, según Krippner (2005), el abrupto desarrollo del sector financiero terminó por desvirtuar su principal función, es decir, la de canalizar los recursos ahorrados por los agentes económicos con superávit, hacia los hogares con deseos de consumir por encima de sus ingresos, $y$ principalmente, hacia las empresas dispuestas a invertir. Bajo esta lógica, los bancos eran los principales intermediarios financieros, recogiendo fondos ahorrados en forma de depósitos, y destinándolos a la inversión y al consumo en forma de préstamos. Sin embargo, ante los cambios llevados a cabo en el sistema financiero, dicha lógica también parece haberse modificado en cierta manera; por ejemplo, de acuerdo con Correa y Girón (2004), los mercados financieros se han vuelto aún más sensibles a las señales que indican ganancias o pérdidas eventuales; por lo que actividades de índole especulativa han sido bien acogidas por las instituciones bancarias, con lo que sus mecanismos para la obtención de ganancias se han desvinculado cada vez más de las bases productivas; lo que ha contribuido a generar un ambiente de fragilidad e inestabilidad en el ámbito financiero. $Y$ es que mientras en las actividades productivas, los capitales presentan un fuerte arraigo, y, por ende, su fuga espontánea es poco probable; dado que su eficiencia $\mathrm{y}$ rentabilidad queda condicionada al compromiso de largo plazo; en las actividades relacionadas con el ámbito financiero, la lógica es de corto plazo. 16

En este sentido, los inversores institucionales, son un buen ejemplo de dicha lógica, pues se trata de agentes que obtienen grandes rendimientos, a través de la especulación financiera; es decir, los recursos financieros son

pronosticar el fin de dicha etapa, para inmediatamente abandonar retirar las inversiones, por lo tanto, existe poco o nulo compromiso con el crecimiento económico de largo plazo. 
reinvertidos en actividades financieras, $y$ es precisamente este actuar, lo que termina por reducir la inversión productiva (Duménil y Lévy, 2004). 17

Gráfico 1. Índice de cotizaciones de las principales Bolsas de América.
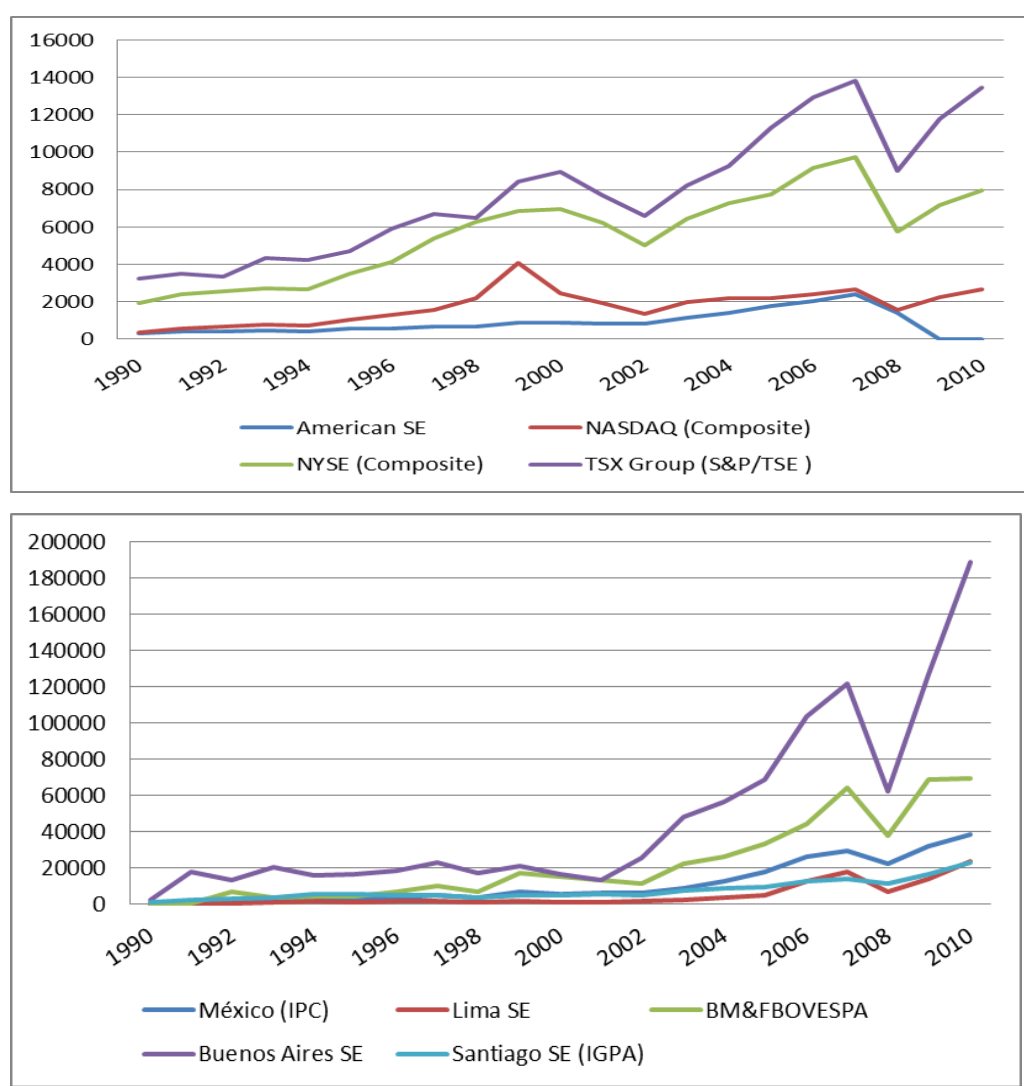

Fuente: Elaboración propia con base en datos de la CNBV (2016).

Porque ante la constante exigencia que se le hace a la inversión de mantener costos mínimos y una tasa de rentabilidad segura; el capital no encuentra destino suficientemente rentable en la de tipo productiva, y, por ende, se desplaza a los diferentes mercados financieros (véase gráfico 1 del anexo estadístico). En este sentido, es que Foster (2007) sostiene que el estancamiento

17 Los inversores institucionales se clasifican fundamentalmente en tres categorías, de acuerdo a su campo de operación: en fondos de pensión, de inversión y compañías de seguros. En síntesis, su actividad se reduce a vender rápidamente los títulos que reciben; y así, obtener el mayor margen de ganancia posible. Los títulos con los que operan, y que representan sus activos financieros, a su vez, son los pasivos financieros de empresas, gobiernos y familias; de esta manera, la inestabilidad productivo obedece en cierta medida al proceso de financiarización, lo que resulta una contradicción, si se considera que dicho proceso fue parte de la estrategia para revertir la tendencia al estancamiento de las economías desarrolladas a mediados de los setenta.

En el caso de los países subdesarrollados, la década de los noventa es un perfecto ejemplo de los riesgos que guarda un proceso de liberalización financiera, ya que las distintas crisis que experimentaron dichos países, fueron resultado en gran medida de su fragilidad financiera y de la volatilidad característica de los mercados financieros. Además, tras sus respectivos descalabros financieros, estos países debieron lidiar con una pérdida de autonomía en términos de política económica, tanto por la subordinación a los organismos internacionales, derivada de los distintos préstamos recibidos; como por el poder económico que han ganado las instituciones financieras en estos países.18 En este sentido, es importante considerar que los mercados financieros se han convertido en la figura más poderosa de opinión global, por ejemplo, cuando los mercados opinan que determinada política no es la correcta, expresan su desacuerdo a través de la tasa de interés y el tipo de cambio, con lo que complican el éxito de dicha propuesta, es decir, auto cumplen su opinión inicial. De esta manera la política económica queda sujeta a la opinión incierta de los mercados financieros (Crotty, 2005).

El proceso de liberalización financiera, principal detonante del de financiarización, ha acentuado la tendencia intrínseca de los agentes financieros a adoptar posiciones de creciente fragilidad, en aras de mayores beneficios; lo que de acuerdo con Minsky (1986) incrementa el grado de vulnerabilidad económica de las naciones ante choques externos $o$ ataques

del mercado financiero se traslada al sector productivo de la economía (Crotty, 2005).

${ }^{18}$ En el año 2000, las instituciones financieras eran titulares del $57 \%$ del total de la deuda interna de los países emergentes, y para 2005, la proporción había alcanzado el 80\%; en particular, la cantidad de títulos de deuda pública en manos de los bancos aumentó en todos esos paísess (Panceira, 2009). 
especulativos.19 Si se considera que para dicho autor, la inestabilidad económica es ineludible, ya que es resultado de los periodos de estabilidad, que por lo general implican un relajamiento de los márgenes de seguridad y un incremento de los créditos especulativos y de tipo Ponzi; la nueva lógica que caracteriza al ámbito financiero, no hace más que profundizar la nociva tendencia antes descrita. De hecho, es precisamente esta, una de las explicaciones más sólidas para entender la crisis de 2008 en los países desarrollados.

A nivel microeconómico, autores como Crotty (2005), Duménil y Lévy (2005) sostienen que la esfera financiera ha comenzado a detraer recursos que anteriormente estaban destinados al sector productivo, principalmente a través de tres estrategias: aumentando el porcentaje del beneficio empresarial destinado a dividendos, mecanismos de recompra de acciones por parte de las propias empresas, y altos tipos de interés real; mismas que han contribuido a reducir los ritmos de acumulación, y con ello han generado una serie de efectos nocivos, por ejemplo, la tendencia creciente de los niveles de desempleo, característicos de los últimos años; cuyo costo social, en el caso de los países subdesarrollados es aún más grave.

Es decir, el proceso bajo análisis no solo ha generado efectos en el ámbito financiero, sino que también en las actividades productivas. De acuerdo con Lapavistas (2007), ha modificado el funcionamiento y la estructura de las empresas, induciéndolas por un lado a disminuir su tamaño, en aras de reducir costos; y por el otro a incrementar el pago de dividendos a los accionistas; más que a generar reservas y ganancias, con lo que la reinversión productiva se ve comprometida. Así, nuevamente la lógica basada en la búsqueda fácil de ganancias a corto

19 Los activos financieros han contribuido a generar incertidumbre y riesgos crecientes en el sistema financiero global; al grado de que se ha denominado a la crisis de 2008, como "la primera crisis sistémica del nuevo régimen de acumulación financiera", debido a que su origen se relaciona con el nuevo funcionamiento del sistema financiero y el proceso de financiarización. Es decir, el origen de la crisis va más allá de la caída en los precios del sector inmobiliario o los malos deudores; su raíz se encuentra en la especulación basada en la expansión de plazo, se impone; los casos de contabilidad creativa, son un buen ejemplo de ello. De esta manera, se ha modificado la orientación estratégica de las empresas, respecto a la asignación de los recursos y las ganancias, pasando de un modelo 'retener e invertir', hacia uno de 'reducir y distribuir'.

Dicho modelo ha sido acompañado de un nuevo criterio de gestión empresarial, que Hancké (2006) denomina como "Corporate governance", y que tiene la característica de depositar el control de la empresa en agentes externos a la misma, principalmente en los relacionados con el ámbito financiero; que por su naturaleza relegan a segundo plano la generación de ganancias estables de largo plazo, relacionadas con la capacidad productiva de la empresa; lo que de acuerdo con Jeffers y Plihon (2001), compromete la viabilidad de esta, debido a que implica un rediseño de su organización interna, encaminado a satisfacer las demandas de la rentabilidad bursátil y no a mejorar los procesos y resultados relacionados con la producción. Además, al exigirle un mínimo de rentabilidad, la empresa queda obligada a disminuir costos, a través de su contracción, que implica despido de trabajadores, reducción de salarios, intensificación del trabajo, entre otras medidas, que actúan en decremento de la productividad futura de la empresa, única vía hacia su estabilidad de largo plazo. 20

De acuerdo con Lapavitsas (2007), otro de los efectos del proceso de financiarización, se relaciona con los canales de financiamiento de las empresas, ya que al contrario de lo que se esperaba, la liberalización financiera no logró diversificar sus opciones en este rubro, por ejemplo, el acceso de la mayoría de las empresas al mercado bursátil sigue siendo muy restringido. Sin embargo, lo que si se diversificó fue el destino de las ganancias de las grandes empresas, que

la titulización, uno de los pilares del proceso de financiarización económica (Kregel, 2008 y Guttman, 2008).

\footnotetext{
${ }^{20} \mathrm{El}$ nuevo criterio de gestión impide a las empresas llevar a cabo políticas de diversificación, dado que estas dificultan la posibilidad de trasladar y volver líquidos los portafolios financieros y accionarios, es decir, la lógica industrial se contrapone a la financiera (Guttmann, 1996).
} 
identificaron en diversos instrumentos financieros, una opción para incrementar de forma rápida y relativamente sencilla su margen de ganancia; por lo tanto, en un inicio, esto permitió la obtención de importantes niveles de rentabilidad, pero a mediano y largo plazo, implicó un elevado costo en términos de vulnerabilidad.

Por otro lado, las empresas con acceso a financiamiento proveniente de los mercados financieros, también ven comprometida su estabilidad, primero, porque generalmente se ven obligadas a acudir al mercado a refinanciar sus deudas, a una tasa de interés mayor; segundo, porque padecen el desfase entre los plazos de sus activos y obligaciones, que normalmente son más cortos los de estas últimas; y tercero, porque se ven estrechamente vinculadas a los cambios abruptos del mercado financiero, cuyas consecuencias para el aparato productivo son costosas, dado que no son de carácter pasajero (Anguiano, 2012).

De esta manera, el proceso de financiarización ha propiciado el desarrollo de actividades de índole especulativa en el seno productivo; por un lado, modificando el criterio de gestión empresarial; y por el otro, promoviendo nuevas modalidades de financiamiento, que atentan contra la estabilidad económica de las empresas en el largo plazo. La situación descrita empata con el primer teorema de la hipótesis sobre la inestabilidad financiera de Minsky (1986), mientras que el segundo de dichos teoremas, parece describir perfectamente lo sucedido en la mayoría de los países durante las últimas dos décadas: "tras una prosperidad prolongada, la economía transitará de relaciones financieras que generan estabilidad, a relaciones financieras que conducen a la inestabilidad".

De acuerdo con Hancké (2006), el proceso de financiarización ha propiciado que las empresas se comporten más como agentes del mercado financiero, que, como unidades de producción y desarrollo social, lo que ha

${ }^{21}$ Que los salarios reales hayan registrado un ritmo de crecimiento inferior al de la productividad, explica la tendencia generado una serie de efectos en la dinámica laboral, que han terminado por afectar negativamente al salario, con los costos en términos de calidad de vida que ello implica. Y es que si bien es cierto que el proceso de financiarización ha logrado su principal objetivo, es decir, contrarrestar la crisis de rentabilidad que se gestó en los años setenta, resulta innegable que también ha contribuido en la gestación de una serie de aspectos negativos; por ejemplo, un mayor grado de concentración de la riqueza; una progresiva desvinculación entre la productividad, las ganancias y los salarios repartidos, y es que mientras las dos primeras han aumentado, los salarios no lo han hecho en la misma proporción; lo que adquiere relevancia si se considera que precisamente dicho vínculo constituye uno de los más importantes mecanismos de distribución de la riqueza (Huerta, 2011) 21. Por ejemplo, en el caso de México es evidente el debilitamiento que muestra el comportamiento del salario mínimo a lo largo de las últimas tres décadas, como puede observarse en el gráfico 2 del anexo estadístico.

Gráfico 2. Salario Mínimo Real. México (Variación respecto al periodo inmediato anterior).

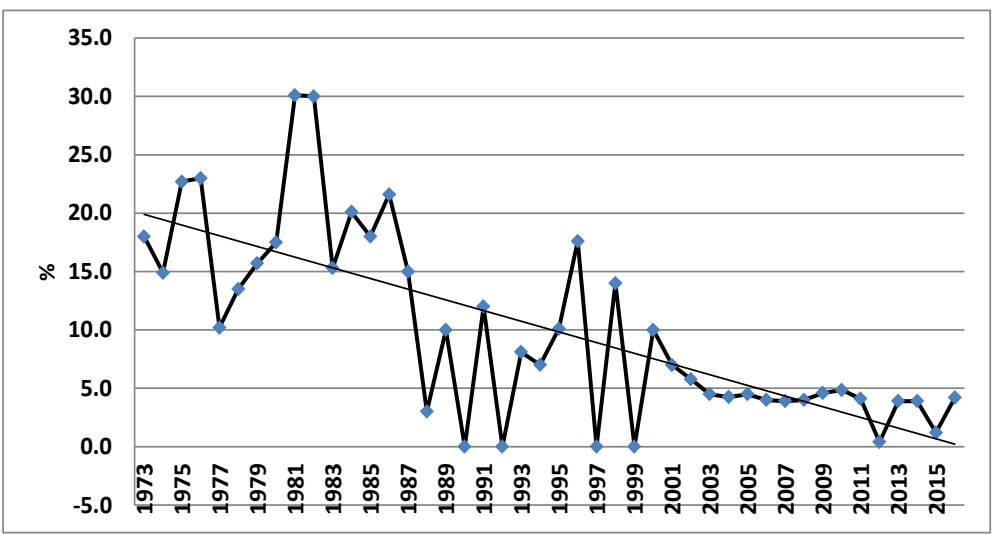

Fuente: Elaboración propia con base en datos de INEGI (2016).

En este sentido, Plihon (2004), considera que el incremento del porcentaje de participación

decreciente de las rentas salariales respecto al PIB, en la mayoría de los países (Huerta, 2011). 
del crédito bancario en el total del ingreso familiar, es un indicador de la reducción de los salarios; es decir, para los trabajadores se ha vuelto indispensable el endeudamiento bancario para la manutención de su consumo.22 Situación que se agrava si se considera que el crédito al consumo no produce valor para su reembolso con intereses; por lo que el pago de estos, deriva del ingreso futuro, con lo que el trabajador queda sujeto a esa dinámica de endeudamiento; que además, resulta ser desigual, ya que por un lado, implica a un especialista en manejo del dinero que trata de maximizar sus ganancias y, por el otro, a un asalariado que pretende asegurar su acceso al consumo.

Gráfico 3. Crédito al consumo, cartera vigente vía la banca comercial (millones de pesos).

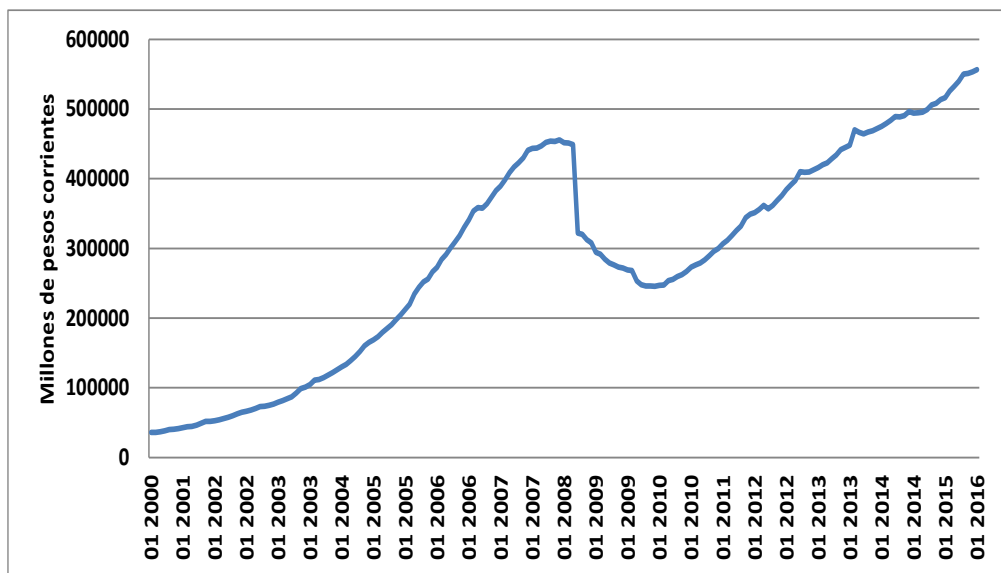

Fuente: Elaboración propia con base en las series históricas del Banco de México (2016).

De esta manera se le permite a la banca fijar tasas de interés elevadas; y de acuerdo a Plihon (2004), el creciente nivel de endeudamiento de los trabajadores, implica una transferencia de sus ingresos, a los bancos y otras instituciones financieras. En contraparte, la banca se ha hecho cada vez más dependiente del crédito al consumo, y de la extracción directa de ingresos; lo que explica la gran promoción que se ha hecho de este tipo de crédito, propiciando el sobreendeudamiento de la población. Por

${ }^{22}$ En Estados Unidos, el porcentaje del ingreso personal disponible que en promedio se dedica a pagar el servicio de deuda, pasó de $15.6 \%$ en 1983 a $19.3 \%$ en 2007 . Y en países subdesarrollados, la propensión al ahorro se redujo, como ejemplo, en el caso de México es notable la tendencia creciente que presenta tanto la cartera vigente, como la vencida de la banca comercial; como puede observarse en los gráficos 3 y 4 del anexo estadístico.

Gráfico 4. Crédito al consumo, cartera vencida vía la banca comercial (millones de pesos).

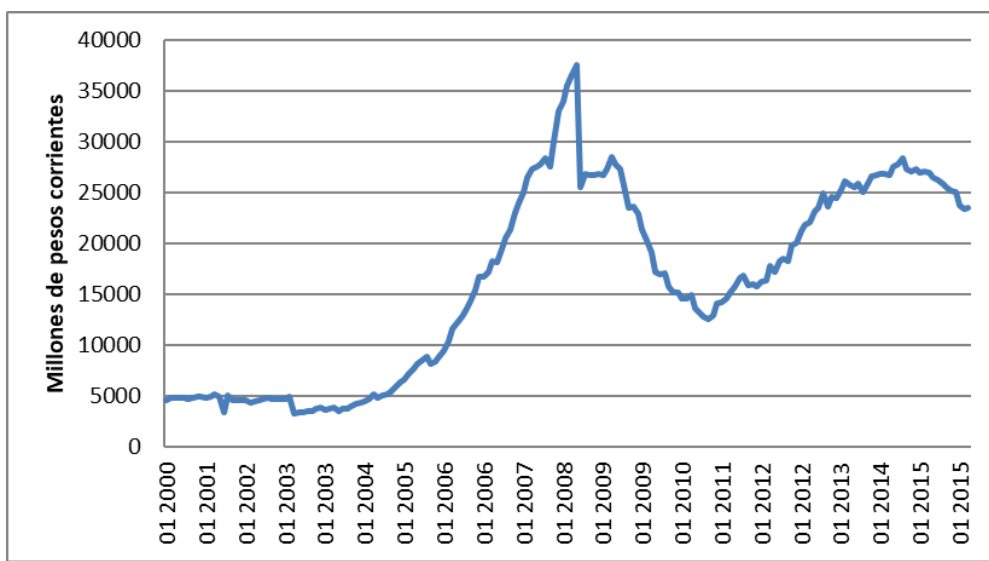

Fuente: Elaboración propia con base en las series históricas del Banco de México (2016).

Además, de acuerdo con Bryan, Martin y Rafferty (2009), la nueva lógica para la obtención de ganancias, también ha significado costos en términos de empleo, por ejemplo; incremento del nivel de desempleo, como resultado de las externalizaciones, subcontrataciones, fusionesadquisiciones y la reducción de la reinversión productiva; un menor poder de negociación por parte de los trabajadores, que se ha traducido en un empeoramiento de las condiciones laborales; y cambios en las fórmulas tradicionales de remuneración (incremento de la parte variable del salario), lo que tiene como objetivo compartir el riesgo de la empresa con su planta laboral, riesgo que se ve potenciado si la empresa decide participar en actividades de índole financiera. Lo que no solo implica para la empresa, cierta pérdida de independencia en su gestión de mediano y largo plazo, sino que, si se consideran los intereses de los trabajadores y de los agentes financieros, probablemente se observe cierto

resultado de financiar el consumo a través de deuda (Kremp, 2008). 
conflicto entre ellos, dado que los primeros preferirán estabilidad $\mathrm{y}$, por ende, inversiones seguras; los segundos optaran por maximizar el beneficio en el corto plazo, ante lo cual, las operaciones de carácter especulativo se tornan muy atractivas.

\section{Conclusiones}

Actualmente la economía internacional enfrenta las consecuencias de la que se considera la crisis más importante en la historia del periodo capitalista, la primera de la era caracterizada por el proceso de globalización, y también por el de financiarización económica. Este último, de acuerdo con diversos autores, responsable de la mayoría de los descalabros financieros ocurridos durante los últimos veinte años; dado que representó una transformación sistémica de la economía capitalista, en aras de incrementar el nivel de ganancia, sin considerar los costos de dicha lógica.

El indicador más evidente de la evolución del proceso bajo análisis es el extraordinario crecimiento del sector financiero, sin embargo, no es posible reducir este fenómeno al incremento de las variables financieras, dado que el dominio de la lógica financiera sobre la dinámica económica ha generado una serie de cambios, no sólo en el sector financiero, sino también en el productivo, con sus respectivos impactos sobre la calidad de vida de la población.

Hasta ahora es posible identificar tres rasgos esenciales respecto a este proceso: el crecimiento del sector financiero en los últimos años ha sido mayor que el del sector productivo; se ha incrementado el grado de participación en actividades financieras, por parte de empresas no financieras; y cada vez son más los autores que señalan el inicio de una transferencia de recursos, del sector productivo al financiero, que reduce la inversión productiva de largo plazo. A partir de estas ideas, resulta evidente que la relación entre ambos sectores es de tal magnitud que determina la evolución de ambos, por lo que en trabajos posteriores se buscará identificar los vínculos y efectos de dicha relación, principalmente en países subdesarrollados, como es el caso de la economía mexicana.

Respecto al origen del proceso, existe cierto consenso sobre el hecho de ubicarlo en la economía estadounidense, durante la década de los setenta, y es que las políticas que lo configuraron, representaron en dicho momento, la respuesta ante el estancamiento económico que se padecía. Posteriormente, dichas medidas fueron el eje de la llamada "revolución conservadora", cuyo principal objetivo fue revertir la tendencia de la rentabilidad, es decir, recomponer las condiciones propicias para la valorización del capital, por ejemplo, fomentando una generalizada privatización, desreglamentación, liberalización y apertura comercial irrestricta de las distintas economías. Finalmente, la globalización financiera, el progreso tecnológico en materia de información, y la constante innovación financiera, terminaron por configurar una nueva dinámica económica, en la que la lógica de las finanzas se tornó dominante.

En relación con los efectos derivados del proceso de financiarización, existen dos principales posturas, la primera sostiene que el desarrollo de la esfera financiera tiene un impacto positivo sobre el sector productivo, a través de la reducción del costo del capital, y de una mejor asignación de este. Sin embargo, los detractores de este argumento, enfatizan lo siguiente, para que dichas ventajas en realidad se materialicen, son necesarios cuantiosos flujos de capital, mismos que terminan por desestabilizar a la economía que los recibe, dado su alto componente especulativo; las crisis de los países emergentes durante la década de los noventa, son buen ejemplo de ello. Además, dichos flujos, han implicado para estos países, una pérdida de autonomía en términos de política económica, imposibilitándolos para implementar políticas que realmente contribuyan a su desarrollo y crecimiento económico.

Así, los efectos de este proceso son diversos, en el ámbito macroeconómico destaca el hecho de que se ha desvirtuado la principal función del sistema financiero; la de canalizar los ahorros a la inversión real. La proliferación de los 
inversores institucionales da cuenta de ello. A nivel microeconómico, los cambios más emblemáticos han sido: la nueva lógica empresarial, que prioriza el reparto de beneficios a los accionistas, sobre la reinversión productiva, comprometiendo la estabilidad de las empresas; así como una mayor dificultad para acceder a las fuentes tradicionales de crédito, ante lo que han ganado terreno nuevas opciones de financiamiento que implican una serie de riesgos, relacionados con la especulación.

De acuerdo con Duménil y Levy (2007) la acumulación capitalista ya no se funda en la inversión que maximice la producción, sino sólo en aquella que consiga hacerla rentable, aún a costa de contenerla, dado que opta por aumentar la tasa de rentabilidad a través de reducir el crecimiento de la composición orgánica del capital, con lo que se sacrifica a la inversión estructurada de largo plazo. Esto ha tenido efectos negativos sobre los niveles de empleo y salario. Lo que ha sido acompañado de una mayor concentración de la riqueza y un creciente endeudamiento por parte de los trabajadores, obligados a recurrir al crédito, que se ha vuelto sustituto del salario, y que representa una nueva modalidad de explotación financiera.

Finalmente, es importante señalar que de ninguna manera se busca establecer que las finanzas son inútiles o parasitarias por naturaleza. Estas desarrollan funciones esenciales en las transacciones monetarias y financieras, con las que contribuyen a la movilidad del capital entre las diferentes empresas y ramas, organizan las reestructuraciones de las empresas y facilitan al financiamiento. Sin embargo, las últimas décadas parecen mostrar un cambio perverso en su estructura y funciones, que atenta contra la estabilidad de la economía global. La crisis de 2007-08, da cuenta de los riesgos implícitos de una dinámica económica en la que se prioriza la ganancia de corto plazo, que sólo es posible obtener a través de prácticas especulativas. Economías como la mexicana, pese a que su sistema financiero no es tan desarrollado como el estadounidense, presentan ya una clara tendencia a sumarse a dicha dinámica; por lo que analizar el proceso de financiarización económica se torna imperativo.

\section{Referencias}

Aglietta, M. (2000) "Shareholder Value and Corporate Governance: Some Tricky Questions". París. Economy and Society, No. 29.

Anguiano, E. (2012) "Mercados Financieros Internacionales". México. Universidad Nacional Autónoma de México.

Arrighi, G. (1999) "El largo siglo XX: dinero y poder en los orígenes de nuestra época". México D.F. Traducción Facultad de Economía.

Arrighi, G. y Beverly J. (2001) "Capitalism and world (dis)order". Review of International Studies, No. 27

Aspe, P. (1993) "El camino mexicano de la transformación". México, Ed. FCE

Boyd, B; Howard, G; y Pendleton, A. (2005) "Finance, Corporate Governance, and Labour, Evidence from OCDE countries". Londres.

Boyer, R. (2000) "Is a Finance-led Growth Regime a Viable Alternative to Fordism? A Preliminary Analysis". París. Economy and Society, No. 29.

Bryan, D; Martin, R; y Rafferty, M. (2009) "Financialization and Marx: Giving labor and capital a finacial makeover". Review of radical political economics, no. 41.

Buffie, E. (1984) "Financial repression, the new Structuralist, and stabilization policy in semiindustrialized economics". Journal of Development Economics, vol. 14 No. 3

Chesnais, F. (coord.) (1999) "La mundialización financiera. Génesis, costes y desafíos". Buenos Aires. Ed. Losada.

Chesnais, F. (2003) "La teoría del régimen de acumulación financiarizada: contenido, alcance e interrogantes". Valladolid. Revista de Economía Crítica, No. 1.

Correa, E. y Girón, A. (2004) "Desregulación y Crisis Financieras", en Correa, E. y Girón, A. (coord.) (2004) Economía Financiera Contemporánea, tomo I. México D.F. Ed. Miguel Ángel Porrúa. 
Coutrot, T. (1998) "L’entreprise néo-libérale, nouvelle utopie capitaliste?". París.

Crotty, J. (2005) "The Neoliberal Paradox: The Impact of Destructive Product Market", en Epstein, G. Financialization and The World Economy. Londres.

De Boissieu, C. (2004) "Les systèmes Financiers. Mutations, crises et régulations". París.

Duménil, G. y Lévy, D. (2004) "Capital Resurgent. Roots of the Neoliberal Revolution". Massachusetts. Harvard University Press.

(2007) "Crisis y salida de la crisis".

México. Fondo de Cultura Económica.

Eatwell, J. (2000)."Global Finance at Risk". Cambridge. Polity Press.

Epstein, G. (2005) "Financialization and the World Economy". Londres. Ed. Edward Elgar Publishing.

Foster, J. (2007) "Financialization of Capitalism". Nueva York. Monthly Review, No. 11.

Froud, J; Ojal, S; Leaver, A. y Williams, K. (2006) "Financialization and Strategy". Londres.

Goldsmith, R. (1969) "Financial Structure and Development". New Haven. Yale University Press.

Guttman, P. (1996) "La Mondialisation Financière". París.

Hancké, B. (2006) "Labour in French Corporate Governance, The missing Link". Oxford. Oxford University.

Huerta, A. (2011) "La crisis en EUA y México: La dificultad de su salida”. México. Universidad Nacional Autónoma de México (UNAM).

Huffschmid, J. (2002) "Redistribution, marches financiers et contre-réforme". París.

Husson, M. (2008) "Finance, hyperconcurrence et reproduction du capital" París, Editions Page Deux.

Jeffers, E. y Plihon, D. (2001) "Investisseurs institutionnels et gouvernance des entreprises". París. Revue d’Economie Financière no. 63.

Kregel, J. (2007), "The Natural Instability of Financial Markets". Nueva York. The Levy Economics Institute. Working Paper no. 523.
Kremp, P. (2008) "From Main street to Wall street? The detrminats of Stock.Market Participation and their Evolution from 1995 to 2007". Princeton. Princeton University.

Krippner, Greta R. (2005) "The Financialization of the American Economy". Oxford. Socio-Economic Review, No. 3.

Lapavitsas, C. (2007) "Financialised Capitalism: Expansion and Crisis". Madrid. Ed. Maia. (coord.) (2011) "La crisis de la financiarización". México. Universidad Nacional Autónoma de México.

Levine R. (1995) "¿Es importante el sistema financiero?, Crecimiento económico: teoría, instituciones y experiencia internacional". Bogóta

Levine, R. (2004), "Finance and growth: theory and evidence". Cambridge, Massachusetts. National Bureau of Economic Research (NBER), Working Paper Series, N 10766.

Lucas, R. (1988) "On the mechanics of economic developments". Journal of monetary economics, no. 22.

Magdoff, H. y Sweezy, P. (1969) "The Age of Imperialism: The Economics of US Foreign Policy, New York"; en Monthly Review Press.

Magdoff, H. y Sweezy, P. (1983) "Estancamiento y explosión financiera en Estados Unidos". Nueva York. Ed. Siglo XXI.

McKinnon, R. (1973) "Money and Capital in Economic Development". Washington, D.C. Brookings Institution Press.

McKinsey, (2008) "Mapping global capital markets". 4th Annual Report. McKinsey Global Institute.

Medialdea, B. (2003) "Inestabilidad financiera en las economías emergentes latinoamericanas en los años noventa: el caso de Brasil". Madrid. Facultad de Ciencias Económicas y Empresariales, UCM.

Minsky, H. (1986) "Stabilizing an Unstable Economy". Connecticut. Yale University Press.

Orhangazi, O. (2008) "Financialization and the US Economy". Massachusetts. Ed. Edward Elgar Publishing.

Odedokun (1996) "Alternative econometric approaches for analyzing the role of the financial sector in econometric growth: Time series evidence 
fron LDCs". Journal of development Economics, vol. 50, no. 1 .

Orléan, A. (1999) "Le pouvoir de la finance". París. Editions Odile Jacob.

Palazuelos, E. (1998) "La globalización financiera". Madrid. Ed. Síntesis.

Palley, T. (2008) "Financialization: What it is and Why it Matters". Nueva York. The Levy Economics Institute, Working Paper No. 525

Painceira, Juan (2009) "Developing countries in the era of financialisation: From deficit accumulation to reserve accumulation". Research on money and finance discussion no. 4.

Plihon, D. (2004) "El nuevo capitalismo". París. Ed. Siglo XXI.

Ponssard, J. (2002) "Monteé en pissance des fonds d'investissement. Quels enjeux pour les entreprises?". París. La documentation francaise.

Reberioux, A. (2003) "Les marchés financiers et la participation des salariés aux décisions". París.

Robinson, J. (1952) "The generalisation of the general theory", en The rate of interest and other essays. Londres. Ed. Macmillan.

Ryoo, S. y Skott, P. (2008) "Financialization in Kaleckian economies with and without labor constraints". Massachusetts. UMASS Amherst Economics Working Papers University of Massachusetts Amherst, Department of Economics.

Salama, P. (1997) "Financiarización excluyente en las economías latinoamericanas". México.

Sauviat, C. (2001) "L'Impact des marches financiers sur la gestión des ressources humaines: une enquête exploratoire auprès de grandes entreprises françaises". París.
Shaw, E. (1973) "Financial Deepening in Economic Development", Nueva York. Oxford University Press.

Stiglitz, J. (2002) "Globalization and Its Discontents". Nueva York.

Stockhammer, E. (2004) "Financialization and the Slowdown of Accumulation". Cambridge. Journal of Economics No. 28.

Stockhammer, E. (2009) "The financedominated growth regime, distribution, and the present crisis". Vienna. University of Economics.

Swary, I. y Topf, B. (1993) "La desregulación financiera global". México. Fondo de Cultura Económica.

Sweezy P. (1994) "The triumph of financial capital". En Monthly Review, vol. 46, no. 2.

Tinoco, M; Torres, V; y Venegas, F. (2008) "Deregulation, financial development and economic growth in México: Long term effects and causality". Nueva York.

Tobin (1984) "On the Efficiency of the Financial System". En Lloyd's Bank Review, no. 153.

Wijngergen, S. (1983) "Credit policy, inflation and growth in financially repressed economy". Journal of Development Economics, vol. 13, no. 1-2.

$\mathrm{Xu}$, Z. (2000) "Financial Development, investement and economic growth". Economic Inquiry, vol. 38, no. 2. 